\title{
Raw garlic (Allium sativum) improves nonspecific immune responses and resistance against Vibrio alginolyticus infection in grouper (Epinephelus coioides)
}

Huai-Ting Huang

National Taiwan Ocean University, Taiwan, ROC

Po-Tsang Lee

National Taiwan Ocean University, Taiwan, ROC

Zhen-Hao Liao

National Taiwan Ocean University, Taiwan, ROC

Cheng-Ting Huang

National Taiwan Ocean University, Taiwan, ROC

Hsiang-Yin Chen

National Penghu University of Science and Technology, Penghu, Taiwan ROC

See next page for additional authors

Follow this and additional works at: https://jmstt.ntou.edu.tw/journal

Part of the Fresh Water Studies Commons, Marine Biology Commons, Ocean Engineering Commons, Oceanography Commons, and the Other Oceanography and Atmospheric Sciences and Meteorology Commons

\section{Recommended Citation}

Huang, Huai-Ting; Lee, Po-Tsang; Liao, Zhen-Hao; Huang, Cheng-Ting; Chen, Hsiang-Yin; Huang, Zhi-Gu; Nan, Fan-Hua; and Wu, Yu-Sheng (2022) "Raw garlic (Allium sativum) improves nonspecific immune responses and resistance against Vibrio alginolyticus infection in grouper (Epinephelus coioides)," Journal of Marine Science and Technology. Vol. 29: Iss. 6, Article 4.

DOI: $10.51400 / 2709-6998.2555$

Available at: https://jmstt.ntou.edu.tw/journal/vol29/iss6/4

This Research Article is brought to you for free and open access by Journal of Marine Science and Technology. It has been accepted for inclusion in Journal of Marine Science and Technology by an authorized editor of Journal of Marine Science and Technology. 
Raw garlic (Allium sativum) improves nonspecific immune responses and resistance against Vibrio alginolyticus infection in grouper (Epinephelus coioides)

Authors

Huai-Ting Huang, Po-Tsang Lee, Zhen-Hao Liao, Cheng-Ting Huang, Hsiang-Yin Chen, Zhi-Gu Huang, FanHua Nan, and Yu-Sheng Wu 


\title{
Raw Garlic (Allium sativum) Improves Nonspecific Immune Responses and Resistance Against Vibrio Alginolyticus Infection in Grouper (Epinephelus coioides)
}

\author{
Huai-Ting Huang ${ }^{a}$, Po-Tsang Lee ${ }^{a}$, Zhen-Hao Liao ${ }^{a}$, Cheng-Ting Huang ${ }^{a}$, \\ Hsiang-Yin Chen ${ }^{b}$, Zhi-Gu Huang ${ }^{a}$, Yu-Sheng $\mathrm{Wu}^{c}{ }^{c}$, Fan-Hua Nan ${ }^{\mathrm{a}, *}$

\footnotetext{
a Department of Aquaculture, National Taiwan Ocean University, No. 2, Pei-Ning Road, Keelung 20224, Taiwan

${ }^{b}$ Department of Aquaculture, National Penghu University of Science and Technology, No. 300, Liohe Road, Magong, Penghu 880, Taiwan

${ }^{\mathrm{c}}$ Department of Aquaculture, National Pingtung University of Science and Technology, No. 1, Xue-Fu Road, Neipu Township Pingtung Country 912301, Taiwan, ROC
}

\begin{abstract}
Garlic contains various nutrients and healthful ingredients. The content of garlic products is closely related to their processing methods, and each compound has specific biological effects. Allicin, a heat labile compound, is considered the most important factor in garlic. Garlic powder is commonly prepared by subjecting raw garlic to thermal processing before being grounded into powder,and it is of interest to compare the biological activity of garlic powder with raw garlic in fish. This study investigated immune effects of raw garlic and garlic powder on groupers (Epinephelus coioides). Although raw garlic and garlic powder did not promote growth performance of groupers, they increased groupers' survival after fish were challenged with Vibrio alginolyticus, especially for fish receiving $80 \mathrm{~g}$ raw garlic/kg diet. The results indicated that phagocytosis, superoxide anion, and superoxide dismutase activity were significantly enhanced in groupers fed with diets containing raw garlic, and to a lesser extent in fish received garlic powder. No significant differences were found between different treatments in terms of serum albumin concentration or albumin/globulin ratio. Serum globulin concentration was temporarily enhanced in the groupers fed with $10 \mathrm{~g}$ raw garlic/kg diet or $10 \mathrm{~g}$ garlic powder/kg diet. These data suggest that diets with raw garlic and garlic powder could enhance nonspecific immune response of grouper and improve its resistance against $V$. alginolyticus and that immune effect of raw garlic is superior to that of garlic powder.
\end{abstract}

Keywords: Grouper, Garlic, Immunostimulants, Vibrio alginolyticus

\section{Introduction}

G roupers are high-value and commonly cultured fish in aquaculture. The number of grouper species is approximately 160, including Epinephelus salmonoides, Epinephelus fario, Epinephelus malabaricus, Epinephelus coioides, Cromileptes altivelis, and Epinephelus tauvina et al. [1]. E. coioides is extensively cultured in Taiwan. Because of high density farming, pathogen spread rapidly and caused severe economic losses [2].

Diseases in aquaculture animals are mostly controlled using antibiotics and other drugs resulted in pathogens developing resistance to antibiotics and in drug residue in the animals [3]. Many

Received 3 December 2020; revised 22 January 2021; accepted 5 July 2021.

Available online 27 December 2021

* Corresponding author.

E-mail address: fhnan@mail.ntou.edu.tw (F.-H. Nan). 
countries or regions, including Japan, the United States, and the European Union, have been implementing stricter controls on the quality, hygiene, and safety of aquatic products. Therefore, the use of antibiotics and other drugs is gradually eliminated [4]. The fish immune system can be divided into nonspecific and specific elements [5]. The nonspecific immune mechanism is the first defense against foreign pathogens. Immunostimulants including nutritional factors, bacterial preparations, polysaccharides, extracts of animal or plant source, cytokines or chemical agents [6] could enhance effectively nonspecific immune responses and resistance to infectious diseases in aquatic animals [7-9]. Furthermore, the application of immunostimulants can reduce reagent use and prevent reagent residue $[10,11]$.

Garlic contains various nutrients, such as lipids, proteins, vitamins, and many minerals. In addition, garlic contains beneficial and healthful ingredients, such as lectins, prostaglandins, adenosine, biotin, nicotinic acid, fatty acids, glycolipids, phospholipids, anthocyanins, flavonoids, phenolics, and essential amino acids [12]. Numerous studies have indicated that garlic affects diverse physiological mechanisms, including enhancing antioxidant, antibacterial effects and improving immunity in aquatic animals [13-17]. Diets containing garlic powder could also enhance the immunity of Labeo rohita, providing greater resistance to Aeromonas hydrophila infection [13]. Enriching the diets of E. coioides and Rachycentron canadum with garlic powder could enhance their growth performance and counteract Streptococcus iniae infection in a short feeding period [18,19]; however, the potential impacts of long-term dietary garlic supplement on the modulation of innate immune factors and growth performance were not properly investigated in grouper. Furthermore, allicin (diallyl-dithiosulfinate) is considered the most important compound in garlic, but it is also known to be unstable in the presence of heat [20]. As the garlic powder is commonly prepared by subjecting raw garlic to thermal processing before being grounded into powder, it is of interest to compare the biological activities in fish between the supplement of garlic powder and raw garlic. Vibriosis is a common pathogen in aquaculture and could affect all stages of fish development. Vibriosis leads $50 \%$ mortality for fish, and Vibrio alginolyticus is a serious pathogen [21]. Accordingly, the current study examined the immunomodulatory ability of raw garlic or garlic powder on grouper and identified the protective effects of these supplements as prophylactic agents against Vibrio alginolyticus infection. The current findings have implications for the optimization of grouper aquaculture.

\section{Materials and methods}

\subsection{Experimental animals}

The groupers $E$. coioides used in the experiment was obtained from the commercial fish farm. Groupers were acclimatized in the laboratory for about 1 week and were fed twice daily with commercial fish feed before the experimentation. The temperature and salinity conditions of water were maintained at $28 \pm 1{ }^{\circ} \mathrm{C}$ and at $34 \pm 1 \%$.

\subsection{Diet preparation}

Fresh garlic (Allium sativum) was purchased from a local market in Keelung, Taiwan. The garlic was cleaned, peeled, and sliced at room temperature. Two forms of garlic were prepared: raw and powder. For the raw form, the garlic was crushed using a homogenizer. For the powder form, the garlic was oven dried at $45{ }^{\circ} \mathrm{C}$ for $24 \mathrm{~h}$ and ground to obtain powder. For each experiment, the commercial feed was crushed using a homogenizer and mixed directly with garlic to achieve 10,40 , and $80 \mathrm{~g}$ of raw garlic or garlic powder per $\mathrm{kg}$ of feed. The feed of control group contained no garlic. The composition of commercial feed was listed in Table 1. The diet was reformed using a spaghetti squash machine and stored at $4{ }^{\circ} \mathrm{C}$ until use.

\subsection{Growth performance}

A total of 315 groupers $(4.38 \pm 0.41 \mathrm{~g})$ were randomly allocated into 21 tanks for 7 groups in triplicate (45 fish per group). Group 1 was the control group. Groups 2, 3 and 4 received 10, 40 and $80 \mathrm{~g}$ of raw garlic per $\mathrm{kg}$ feed weight, respectively. Groups 5, 6, and 7 received 10, 40, and $80 \mathrm{~g}$ of garlic powder per $\mathrm{kg}$ feed weight, respectively. The diets were provided at $3 \%$ of body weight twice daily. The uneaten feed was collected for the calculation of feed intake. Data on growth performance was

Table 1. Ingredient composition of the commercial feed.

\begin{tabular}{ll}
\hline Ingredient & Composition (\%) \\
\hline fish meal $^{\mathrm{a}}$ & 87 \\
eel meal $^{\mathrm{b}}$ & 10 \\
vitamin premix $^{\mathrm{c}}$ & 3 \\
\hline
\end{tabular}

${ }^{\text {a }}$ fish meal: crude protein $75 \%$, crude lipid $10 \%$.

b eel meal: crude protein $45 \%$, crude lipid $3 \%$, crude fiber $1.2 \%$, Ash $16.5 \%$, moisture $11 \%$, phosphorous $2 \%$.

${ }^{c}$ Vitamin premix $\beta$-carotene $0.1 \mathrm{gm}$, calciferol $0.5 \mathrm{gm}$, vitamin $\mathrm{E}$ $2.5 \mathrm{gm}$, vitamin $\mathrm{K} 0.1 \mathrm{gm}$, thiamin HCL $1.5 \mathrm{gm}$, riboflavin $3 \mathrm{gm}$, pyridoxine $\mathrm{HCl} 0.6 \mathrm{gm}$, vitamin B12 $2 \mathrm{mg}$, nicotinic acid $10 \mathrm{gm}$, ascorbic acid $10 \mathrm{gm}$, folic acid $0.3 \mathrm{gm}$, biotin $5 \mathrm{mg}$, calcium pantothenate $4 \mathrm{gm}$, inositol $10 \mathrm{gm}$, PABA $5 \mathrm{gm}$. 
recorded regularly every 2 weeks by weighing and measuring individual fish from each tank during the 8 -week feeding trial. The amount of feeding diet was adjusted according to the weight of grouper every 10 days. Growth performance and feed utilization were calculated as follows:

weight gain $(\%)=(($ final fish weight $[\mathrm{g}]-$ initial fish weight $[\mathrm{g}]) /$ initial fish weight $[\mathrm{g}]) \times 100 \%$. Feed conversion ratio $(\mathrm{FCR})=$ food consumption $(\mathrm{g}) /$ (final weight $[\mathrm{g}]$ - initial weight $[\mathrm{g}]$ ). Survival rate $(\mathrm{SR}, \%)=($ final fish number/initial fish number) $\times 100 \%$.

\subsection{Challenge test}

The healthy groupers $(3.5 \pm 0.2 \mathrm{~g})$ were divided into 7 groups, with 3 replicates of 10 fish in each group. The groups were the same as those defined in Growth performance section. The diets were provided at $3 \%$ of body weight twice daily. The isolation and injection method for $V$. alginolyticus were conducted in accordance with the procedure described by Lee (Lee et al., 2020). The bacteria were prepared to a final concentration of $2.5 \times 10^{9} \mathrm{cfu} /$ $\mathrm{mL}$. The groupers were fed with experimental diet for 8 weeks and then challenged with $20 \mu \mathrm{L} \mathrm{V}$. alginolyticus through intraperitoneal injection. The groupers of Group 1 (control) were challenged with $20 \mu \mathrm{L}$ phosphate-buffered saline (PBS). The number of surviving fish in each group was recorded over an observation period of 10 days. SR of challenge test was calculated as follows: SR $(\%)=$ (number of survived fish after injection/number of injected fish) $\times 100 \%$.

\subsection{Nonspecific immune response}

A total of 215 groupers $(100 \pm 5 \mathrm{~g})$ were randomly allocated into 7 groups. The groups were the same as those described in Growth performance section. The diets were administered at $3 \%$ of body weight twice daily. Immune parameters were determined for 7 periods, with sampling occurring at $0,2,4,8$, 16,24 , and 30 days after dietary administration in each treatment group. Sampling in each treatment group involved the use of five groupers as replicates. The indicator of immune parament was determinant.

\subsubsection{Leukocyte isolation}

Isolation of leukocytes was performed according to the method of Santarém and Figueras [22]. The head kidney was dissected in petri dishes with Hanks' balanced salt solution (HBSS). The dissected cells were passed through a $100-\mu \mathrm{m}$ filter, and then slowly loaded onto the surface of Percoll (Pharmacia, USA) gradient solution in a $15-\mathrm{mL}$ centrifuge tube. The cells were centrifugated at $400 \times g$ for $40 \mathrm{~min}$ at $4{ }^{\circ} \mathrm{C}$. The leukocytes were isolated and collected at $30 \%$ and $50 \%$ Percoll density gradients and then washed three times using HBSS. The concentration of the leukocyte solution was adjusted to $5 \times 10^{6}$ cells $/ \mathrm{mL}$ in HBSS.

\subsubsection{Phagocytosis}

The detection of phagocytosis rate (PR) and phagocytic index (PI) was performed as previously described [23]. A portion $(200 \mu \mathrm{L})$ of the leukocyte solution $\left(5 \times 10^{6}\right.$ cells $\left./ \mathrm{mL}\right)$ was seeded on glass slides for $90 \mathrm{~min}$ at $30{ }^{\circ} \mathrm{C}$ and then washed with HBSS. The cells were incubated with $200 \mu \mathrm{L}$ of fluorescence beads $\left(5 \times 10^{7}\right.$ beads $/ \mathrm{mL}$, Sigma-Aldrich) at room temperature for $60 \mathrm{~min}$ in the dark. The slides were washed with HBSS, and the cells were fixed with $100 \%$ methanol for $5 \mathrm{~min}$. The slides were stained with $5 \%$ Giemsa for $20 \mathrm{~min}$ and washed with $\mathrm{ddH}_{2} \mathrm{O}$. Finally, the slides were observed under a microscope. PR and PI were calculated using the following formulas, respectively: PR $(\%)=$ (number of phagocytic cells/number of observed cells) $\times 100 \%$ and PI $=$ (number of ingested beads in observed phagocytic cells/number of observed phagocytic cells).

\subsubsection{Respiratory burst experiment}

The leukocytes' superoxide anion $\left(\mathrm{O}_{2}^{-}\right)$production was quantified according to the reduction of nitroblue tetrazolium (NBT) to formazan. A portion $(100 \mu \mathrm{L})$ of the leukocyte solution $\left(5 \times 10^{6}\right.$ cells $\left./ \mathrm{mL}\right)$ was seeded in 96-well microplates and centrifuged at $300 \times g$ for $20 \mathrm{~min}$ at $4{ }^{\circ} \mathrm{C}$. The supernatant was removed, and the leukocytes were treated with $100 \mu \mathrm{L}$ of $0.3 \% \mathrm{NBT}$ solution for $30 \mathrm{~min}$ at room temperature. Next, the NBT solution was removed, and $100 \mu \mathrm{L}$ of $100 \%$ methanol was added to stop the reaction. The microplates were washed three times with $100 \mu \mathrm{L}$ of $70 \%$ methanol, and air dried. The formazan was dissolved by adding $120 \mu \mathrm{L}$ of $2 \mathrm{M}$ $\mathrm{KOH}$ and $140 \mu \mathrm{L}$ of dimethyl sulfoxide. The optical density at $630 \mathrm{~nm}$ was measured using an enzymelinked immunosorbent assay reader.

\subsubsection{SOD}

The liver was homogenized with buffer (1\% PBS, $0.3 \%$ Triton X-100, $1 \%$ glycerol, and $97.7 \%$ distilled water). The lysis buffer was centrifuged at $800 \times g$ for $20 \mathrm{~min}$ at $4{ }^{\circ} \mathrm{C}$. The middle layer was collected and stored at $-80{ }^{\circ} \mathrm{C}$ for analysis. Protein concentration was determined according to the method of 
Bradford. For the measurement of superoxide dismutase (SOD) activity, the RANSOD kit (Randox) was used. SOD activity was calculated as follows:

$\triangle \mathrm{A} / \mathrm{min}$ of standard or sample $=(\mathrm{A} 2-\mathrm{A} 1) / 3$

Inhibition $(\%)=100-\left(\triangle \mathrm{A}_{\text {std }} / \mathrm{min} \times 100 / \triangle \mathrm{A}_{\text {std }} / \mathrm{min}\right.$ or sample min) $\times 100 \%$

\subsubsection{Serum collection}

Blood was collected using a $1-\mathrm{mL}$ syringe with a 25G needle and transferred to a $1.5-\mathrm{mL}$ tube. The tube was subsequently maintained at $4{ }^{\circ} \mathrm{C}$ overnight and centrifuged at $7000 \mathrm{rpm}$ for $25 \mathrm{~min}$. The upper layer (serum) was collected and stored at $-80{ }^{\circ} \mathrm{C}$ for subsequent analysis.

\subsubsection{Serum total protein, albumin, globulin}

Serum total protein and albumin were measured using a biochemical analyzer (Roche Cobas Mira). Globulin was determined using the following formula:

globulin $=$ serum total protein - albumin

\subsection{Statistical analysis}

Statistical analysis was performed using IBM SPSS Statistics package 22.0 (SPSS Inc.). $p<0.05$ was considered as a significant difference as the result of the One-way ANOVA with a subsequent Duncan's multiple range test.

\section{Results}

3.1. Effect of raw garlic or powder supplementation for 8 Weeks on growth performance

The observed weight gain, feed conversion rate, and SR are presented in Table 2. The data indicated that weight gain and feed conversion rate were not significantly different between the experimental groups and the control group. Long-term garlic feeding also did not affect the SR.

\subsection{Susceptibility of grouper to V. alginolyticus infection}

Groups fed with raw garlic exhibited significantly enhanced resistance to $V$. alginolyticus in a dosedependent manner (Fig. 1). Except for the group fed with 40 and $80 \mathrm{~g}$ raw garlic/ $\mathrm{kg}$ diet, no significant difference was observed between other experimental groups and control group. However, the groupers fed with $80 \mathrm{~g}$ raw garlic/ $\mathrm{kg}$ diet had the highest SR after being challenged with $V$. alginolyticus.

\subsection{Effect of feeding raw garlic or powder on nonspecific immune response}

Figure 2 showed the PRs. On day 2, treatment with 10,40 , and $80 \mathrm{~g}$ raw garlic/kg diet significantly increased the PR. On day 4 , the PRs in the groups fed with 10, 40, and $80 \mathrm{~g}$ raw garlic/ $\mathrm{kg}$ diet and in those fed with 40 and $80 \mathrm{~g}$ garlic powder $/ \mathrm{kg}$ diet were significantly increased. On day 8 , the PRs in all treatment groups were significantly higher than that of the control group. On day 16, the PRs in the groups fed with 10 and $40 \mathrm{~g}$ raw garlic/ $\mathrm{kg}$ diet and in those fed with $40 \mathrm{~g}$ garlic powder/ $\mathrm{kg}$ diet increased significantly. On day 24 , the administration of $10 \mathrm{~g}$ raw garlic/ $\mathrm{kg}$ diet and 40 and $80 \mathrm{~g}$ garlic powder $/ \mathrm{kg}$ diet significantly enhanced PR compared with the administration of the remaining treatments. On day 30, the groups fed with 40 and $80 \mathrm{~g}$ garlic powder $/ \mathrm{kg}$ diet exhibited significantly increased PRs compared with the remaining treatment groups. Additionally, the group fed with $80 \mathrm{~g}$ raw garlic/kg diet had the highest PR on day 2 , and the group fed with 10 or $40 \mathrm{~g}$ raw garlic $/ \mathrm{kg}$ diet had the highest PR on day 8. Overall the groups of garlic powder gradually increased PR during feeding trial period.

Table 2. Mean initial weight, final weight, percent weight gain, food conversion ratio, and survival rate of groupers (E. coioides) fed diets with various concentrations of raw garlic and garlic powder for 8 weeks.

\begin{tabular}{|c|c|c|c|c|c|c|}
\hline Treatment & Dose (g/kg diet) & Initial weight (g) & Final weight (g) & Weight gain $(\%)$ & FCR & Survival rate \\
\hline \multirow[t]{2}{*}{ Control } & 0 & $4.38 \pm 0.41^{\mathrm{a}}$ & $22.61 \pm 1.46^{\mathrm{a}}$ & $416.18 \pm 33.22^{\mathrm{a}}$ & $0.90 \pm 0.05^{\mathrm{a}}$ & 100 \\
\hline & 10 & $4.38 \pm 0.41^{\mathrm{a}}$ & $23.45 \pm 1.42^{\mathrm{a}}$ & $435.41 \pm 32.46^{a}$ & $0.89 \pm 0.06^{\mathrm{a}}$ & 100 \\
\hline \multirow[t]{3}{*}{ Raw garlic } & 40 & $4.38 \pm 0.41^{\mathrm{a}}$ & $22.36 \pm 1.13^{\mathrm{a}}$ & $410.55 \pm 25.80^{\mathrm{a}}$ & $0.92 \pm 0.01^{\mathrm{a}}$ & 100 \\
\hline & 80 & $4.38 \pm 0.41^{\mathrm{a}}$ & $23.60 \pm 0.37^{a}$ & $438.71 \pm 8.37^{\mathrm{a}}$ & $0.86 \pm 0.03^{\mathrm{a}}$ & 100 \\
\hline & 10 & $4.38 \pm 0.41^{\mathrm{a}}$ & $23.77 \pm 1.40^{\mathrm{a}}$ & $442.62 \pm 31.90^{\mathrm{a}}$ & $0.88 \pm 0.03^{\mathrm{a}}$ & 100 \\
\hline \multirow[t]{2}{*}{ Garlic powder } & 40 & $4.38 \pm 0.41^{\mathrm{a}}$ & $23.52 \pm 0.24^{\mathrm{a}}$ & $436.97 \pm 5.38^{\mathrm{a}}$ & $0.88 \pm 0.02^{\mathrm{a}}$ & 100 \\
\hline & 80 & $4.38 \pm 0.41^{\mathrm{a}}$ & $22.85 \pm 2.94^{\mathrm{a}}$ & $421.61 \pm 67.13^{a}$ & $0.91 \pm 0.11^{\mathrm{a}}$ & 100 \\
\hline
\end{tabular}

Data in the same column with different letters are significantly different $(p<0.05)$ among different treatments. Data are presented as mean \pm standard deviation. 


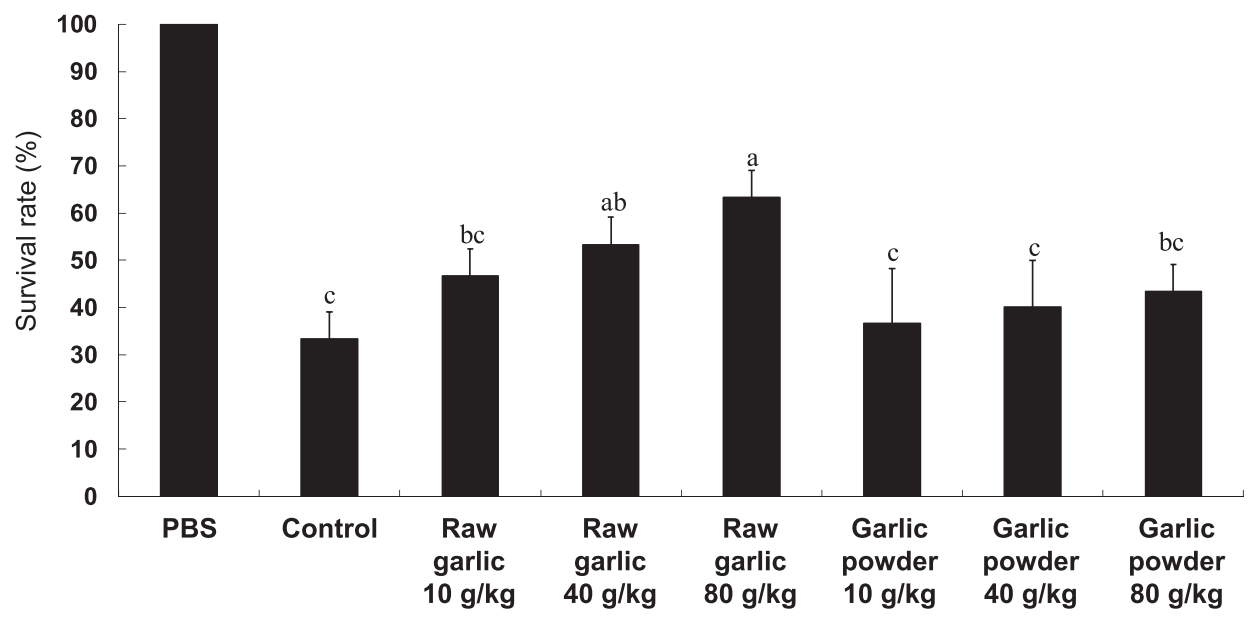

Fig. 1. A Survival of groupers (E. coioides) fed diets with various concentrations of raw garlic and garlic powder for 8 weeks and challenged with $V$. alginolyticus. Bars with different superscripts are significantly different in comparison with each other $(p<0.05)$. Each bar represents the mean value of three replications with the standard deviation (10 groupers per replication).

Figure 3 lists the results of PI. On day 2, the group fed with $80 \mathrm{~g}$ raw garlic/kg diet had the highest PI and higher significantly than other treatments and control group. On day 4, treatment with 10, 40, and $80 \mathrm{~g}$ raw garlic/kg diet significantly increased the PI. On day 8, the PI was significantly increased in the groups fed with 10, 40, and $80 \mathrm{~g}$ raw garlic/ $\mathrm{kg}$ diet and in those fed with 40 and $80 \mathrm{~g}$ garlic powder $/ \mathrm{kg}$ diet. On day 16, treatments with $10 \mathrm{~g}$ raw garlic/ $\mathrm{kg}$ diet and $80 \mathrm{~g}$ garlic powder/ $\mathrm{kg}$ diet exhibited a significantly enhanced PI. On day 24, PI of fish fed with 10, 40 and $80 \mathrm{~g}$ raw garlic/kg diet and 40 and
$80 \mathrm{~g}$ garlic powder/kg diet were significantly increased. On day 30, no significant difference in PI was noted among the groups. Additionally, fish fed with 40 and $80 \mathrm{~g}$ raw garlic/kg diet had the highest PI on day 8 , and fish fed with $10 \mathrm{~g}$ raw garlic/ $\mathrm{kg}$ diet had the highest PR on day 16 . The highest PI of fish that ingested 10, 40 or $80 \mathrm{~g}$ garlic powder $/ \mathrm{kg}$ diet were found on day 16 (Fig. 3).

The $\mathrm{O}_{2}^{-}$production rates of groupers fed with the test diets are presented in Fig. 4. On day 2, the $\mathrm{O}_{2}^{-}$ production rates in the groups fed with 10, 40, and $80 \mathrm{~g}$ raw garlic/kg diet were significantly higher

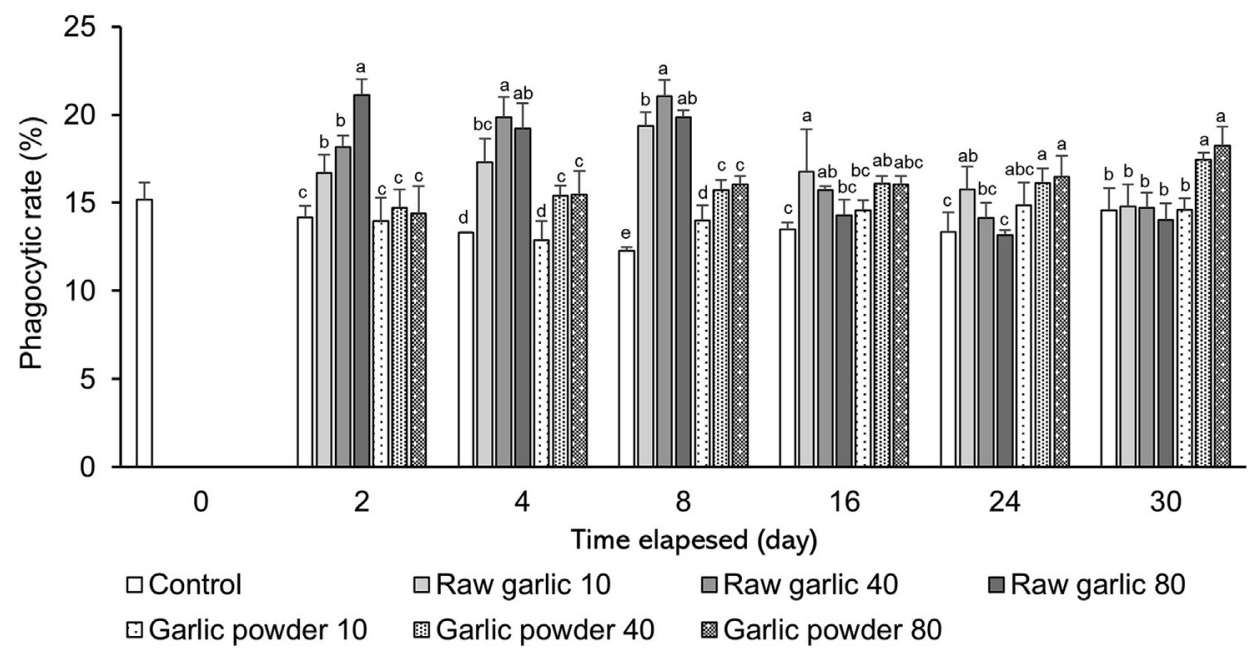

Fig. 2. Phagocytic rate of leukocytes of groupers (E. coioides) fed diets with different concentrations of raw garlic and garlic powder during the culture period. Data with different letters are significantly different $(p<0.05)$ among different treatments. Each bar represents the mean value of five replications with the standard deviation (1 grouper per replication). 


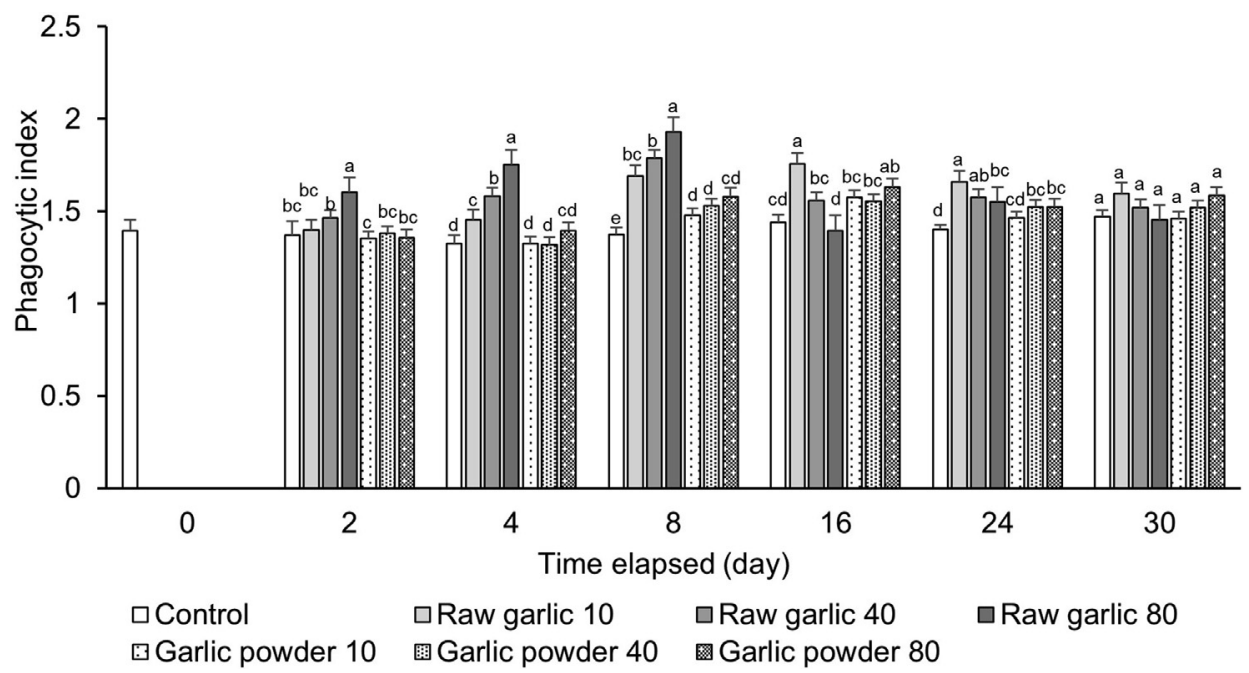

Fig. 3. Phagocytic index (latex beads/cell) of leukocytes of groupers (E. coioides) fed diets with different concentrations of raw garlic and garlic powder during the culture period. Data with different letters are significantly different $(p<0.05)$ among different treatments. Each bar represents the mean value of five replications with the standard deviation (1 grouper per replication).

than that in the control group. On day 4 , treatments with 10, 40, and 80 raw garlic g/ $\mathrm{kg}$ diet and 80 garlic powder $\mathrm{g} / \mathrm{kg}$ diet significantly increased the $\mathrm{O}_{2}^{-}$ production rate. On day $8, \mathrm{O}_{2}^{-}$production increased significantly in the groups fed 10, 40, and 80 raw garlic $\mathrm{g} / \mathrm{kg}$ diet and those fed 10 and 80 garlic powder $\mathrm{g} / \mathrm{kg}$ diet. On day 16, the groups fed 10, 40, and 80 raw garlic $\mathrm{g} / \mathrm{kg}$ diet and that fed 40 garlic powder $\mathrm{g} / \mathrm{kg}$ diet exhibited significant increases in $\mathrm{O}_{2}^{-}$production compared with the control and the remaining groups. Additionally, the $\mathrm{O}_{2}^{-}$production rate was significantly higher than the control group on day 24 and 30, while fish fed with $40 \mathrm{~g}$ raw garlic/ $\mathrm{kg}$ diet. However, the $\mathrm{O}_{2}^{-}$production rate of grouper fed with 10, 40 and $80 \mathrm{~g}$ garlic powder $/ \mathrm{kg}$ diet were significantly higher than the control group on day 2,16 and 30, respectively.

The SOD activity results showed no significant differences was found between control group and treatment groups on days 2, 4 and 16 (Fig. 5). Treatments of 10,40 and $80 \mathrm{~g}$ raw garlic/ $\mathrm{kg}$ diet significantly enhanced its SOD activity on day 8,24 and 30. No significant difference was found in groupers fed with garlic powder at all dosage during the experimental period, while compared with the control group.

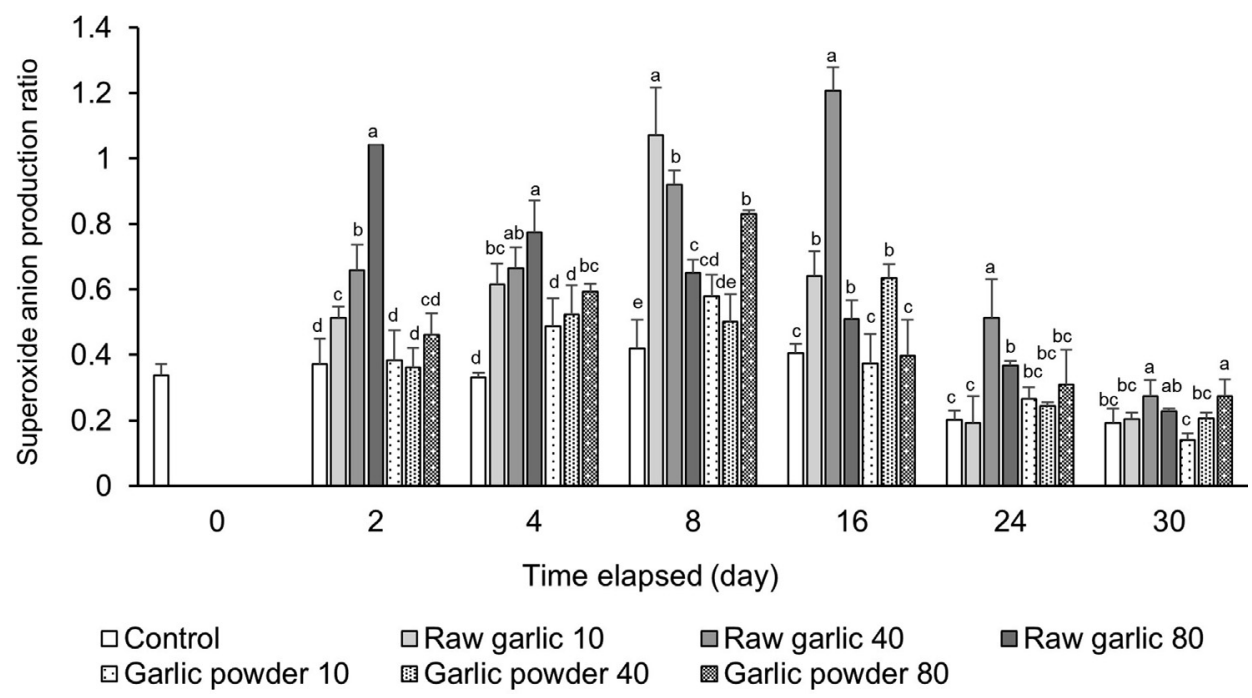

Fig. 4. Superoxide anion production ratio in leukocytes of groupers (E. coioides) fed diets with different concentrations of raw garlic and garlic powder during the culture period. Data with different letters are significantly different $(p<0.05)$ among different treatments. Each bar represents the mean value of five replications with the standard deviation (1 grouper per replication). 


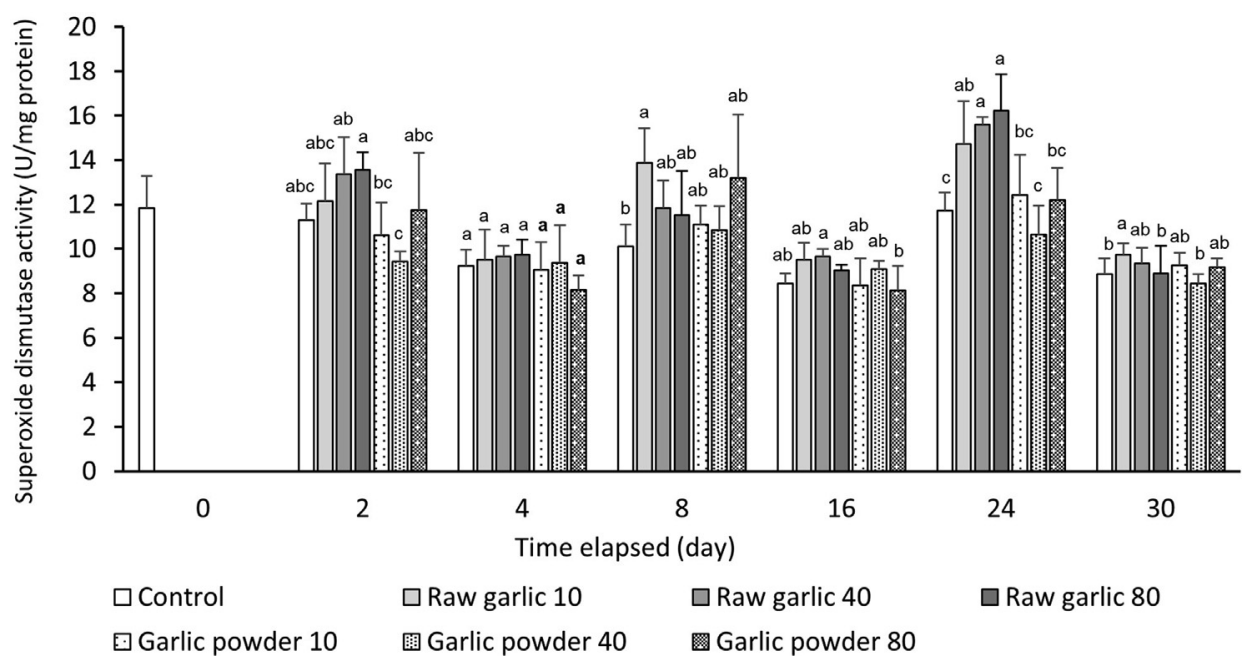

Fig. 5. Superoxide dismutase activity (U/mg protein) in the liver of groupers (E. coioides) fed diets with different concentrations of raw garlic and garlic powder during the culture period. Data with different letters are significantly different $(p<0.05)$ among different treatments. Each bar represents the mean value of five replications with the standard deviation (1 grouper per replication).

For albumin concentrations (Fig. 6) and the albumin/globulin (A/G) ratio (Fig. 7), the results revealed no significant difference between control group and treatment groups. For globulin concentrations (Fig. 8), no significant difference was observed between the control group and treatments except for groupers fed with $10 \mathrm{~g}$ garlic powder $/ \mathrm{kg}$ diet and $10 \mathrm{~g}$ raw garlic/kg diet during the experimental period. The globulin concentration in groupers fed with $10 \mathrm{~g}$ garlic powder/ $\mathrm{kg}$ diet and $10 \mathrm{~g}$ raw garlic/kg diet were higher significantly than the control group on day 4 and 8 , respectively.

\section{Discussion}

Many immunostimulants have been proven to effectively enhance the growth performance and immunity of fish. Garlic as a feed additive can promote the growth performance of grouper $(E$. coioides) [18], sea bass (Lates calcarifer) [24], rainbow
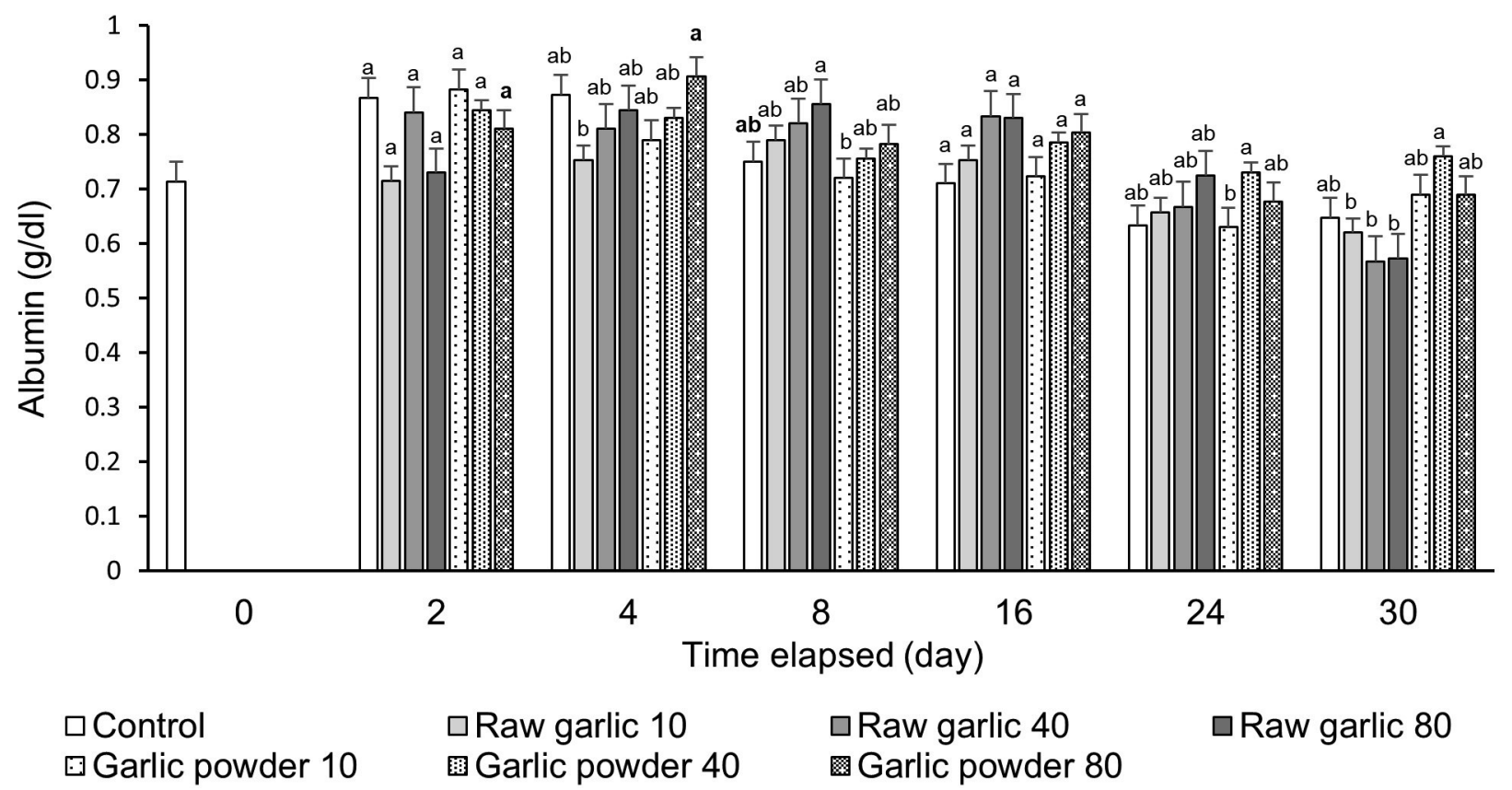

Raw garlic 80

Fig. 6. Albumin ( $g / d l)$ in the serum of groupers (E. coioides) fed diets with different concentrations of raw garlic powder and garlic powder during the culture period. Data with different letters are significantly different $(p<0.05)$ among different treatments. Each bar represents the mean value of five replications with the standard deviation (1 grouper per replication). 


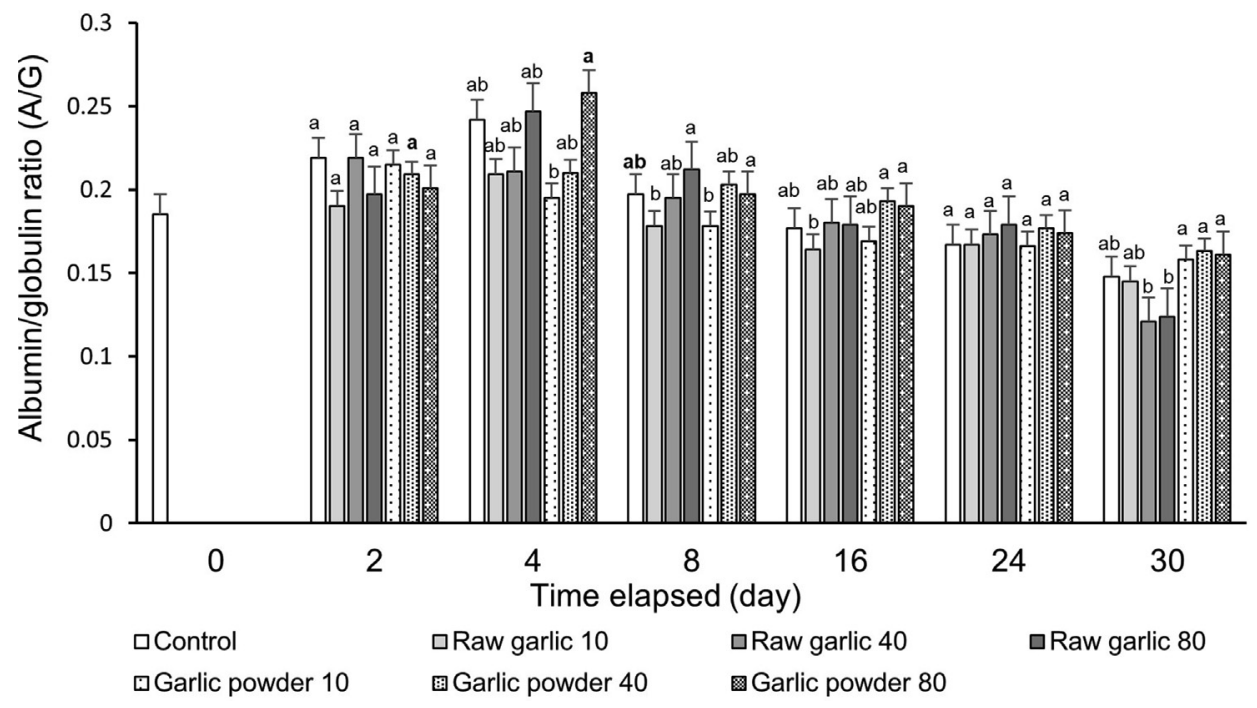

Fig. 7. Albumin/globulin ratio $(A / G)$ in the serum of groupers (E. coioides) fed diets with different concentrations of raw garlic powder and garlic powder during the culture period. Data with different letters are significantly different $(p<0.05)$ among different treatments. Each bar represents the mean value of five replications with the standard deviation (1 grouper per replication).

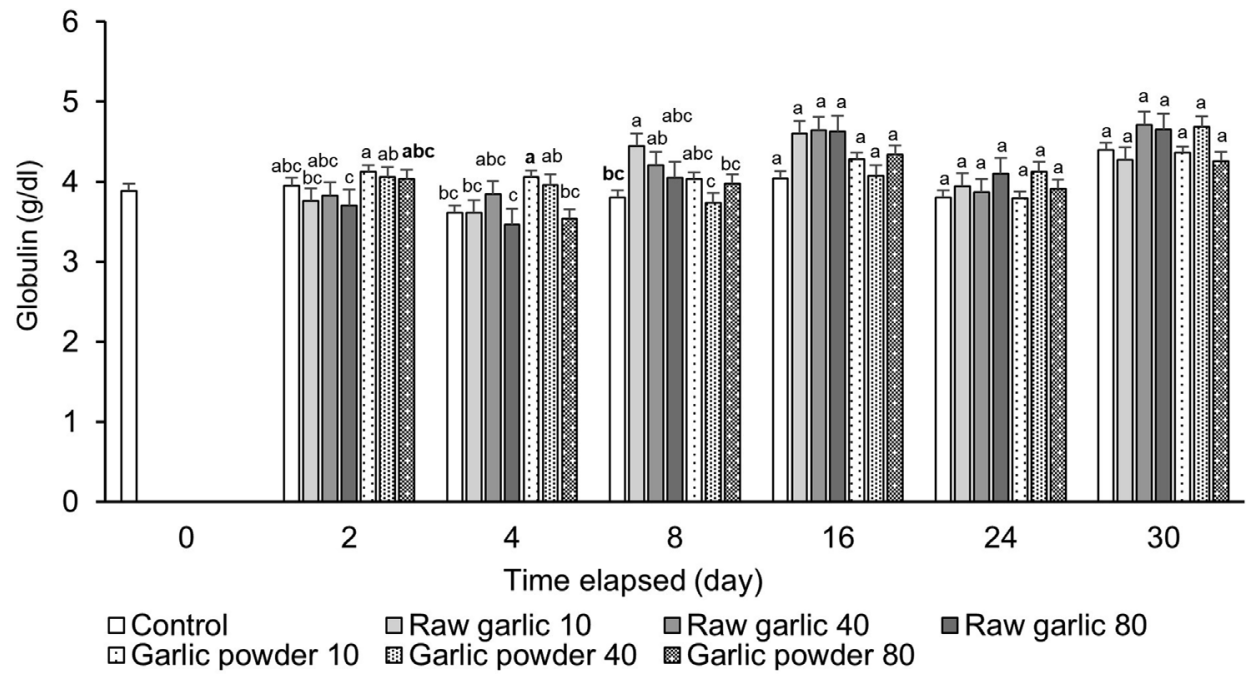

Fig. 8. Globulin $(\mathrm{g} / \mathrm{dl})$ in the serum of groupers (E. coioides) fed diets with different concentrations of raw garlic powder and garlic powder during the culture period. Data with different letters are significantly different $(p<0.05)$ among different treatments. Each bar represents the mean value of five replications with the standard deviation (1 grouper per replication).

trout (Oncorhynchus mykiss) [14], and cobia (R. canadum) [19]. However, in this study, no growth promoting effect was seen in the groupers that were continually fed with raw garlic or garlic powder for 8 weeks at doses ranged from 10 to $80 \mathrm{~g} / \mathrm{kg}$ diet. The discrepancy on growth performance between the present and previous studies may be due to the age and species being studied, feeding period, and the concentration of additive used [25]. It is worthy to note that long term dietary ingestion of garlic supplemented feed had no negative impacts on the growth or SR of grouper regardless the dose and the additive processing methods used, suggesting garlic is safe to be used as feed additive for grouper culture.

Various opportunistic pathogens exist in the environment, including $V$. alginolyticus, bacteria, fungi, and protozoan, which can cause disease when the environment deteriorates or the pathogens multiply in the host [26]. The host's immune system attacks these pathogens, and many immunostimulants have been identified to enhance the diseasefighting ability of the host's immune system. A garlic powder-supplemented diet in $L$. rohita juveniles 
effectively counteracted A. hydrophila infection [13]. A garlic-supplemented diet in E. coioides reduced their mortality after they were challenged by $S$. iniae [18]. The results of the current study revealed that SR of groupers fed with 40 and $80 \mathrm{~g}$ raw garlic powder $/ \mathrm{kg}$ diet for 8 weeks had increased significantly after being challenged with $V$. alginolyticus. Furthermore, the effect of raw garlic was greater than that of garlic powder.

Phagocytosis is a critical nonspecific immune mechanism in fish, and it is a major defense mechanism for removing foreign pathogens [27]. When phagocytosis is triggered, the host produces numerous free radicals such as $\mathrm{O}_{2}^{-}$[28]. The direct participation of free radicals is as a protective mechanism against pathogens, but free radicals may cause damage to the host itself. Therefore, SOD is generated to remove or convert free radicals to reduce oxidative stress [29]. Supplementation with garlic powder can significantly enhance the phagocytic capacity of macrophages in L. rohita [13]. In addition, garlic-supplemented feed could enhance the lysozyme activity of leukocytes in rainbow trout (O. mykiss) [14] and female guppy (Poecilia reticulata) [17]. The similar immunity-boosting effects in this study indicate that the addition of raw garlic and garlic powder to diets can effectively activate the nonspecific immune response of groupers.

Garlic contains many sulfur compounds, including alliin, allicin, diallyl sulfide, and S-allyl cysteine [12], which have immunomodulatory effects. The content and concentration of sulfur compounds in garlic products are closely related to their processing methods and preparation conditions [16], and each compound has specific biological effects $[30,31]$. In this study, the trend and the level of the induction on PR, PI and superoxide anion production were different between groups supplied with raw garlic or garlic powder supplemented diets. For example, fish that fed with $80 \mathrm{~g}$ raw garlic/ $\mathrm{kg}$ diet showed earlier induction and the highest rate of phagocytosis on day 2 , but fish that received the same dose of garlic powder reached the highest level of PR at the last time point examined (day 30). Similarly, the PI of fish fed with raw garlic and garlic powder at the same dose of $80 \mathrm{~g} / \mathrm{kg}$ diet were recorded on day 8 and 16, respectively. This phenomenon was further exemplified in the $\mathrm{O}_{2}^{-}$production. In the group of feeding with the highest dose of garlic, a sharp induction of $\mathrm{O}_{2}^{-}$production was noted on day 2. While fish was given raw garlic supplemented feed, the garlic powder group reached the top level until day 8 . Moreover, the SRs of fish fed with raw garlic were higher than those of fish fed with garlic powder after being challenged with $V$. alginolyticus. Therefore, garlic can enhance the immune function of groupers and then improve their disease resistance, but the bioactive components (e.g. allicin) in garlic are heat labile and cautious should be taken in the garlic additive preparation. In addition, all immune indicators were improved after feeding with the diet containing garlic during early sampling times, but not at late time points such as days 24 and 30 . The phenomenon could be due to the "immunomodulation" [32]. Continued immunostimulation may cause inflammation, thus immunomodulation will be carried out to maintain homeostasis [33]. However, groupers fed with the containing garlic diet for 8 weeks have high SR after vibrio injection. The result identified that garlic could activate grouper's immune system for longer feeding period.

The proteins in blood can be divided into two major groups: albumin and globulin. Albumin, mainly synthesized by the liver, helps maintaining the osmotic pressure of blood [34]. Globulins, produced by the liver or the immune system, are involved in immune mechanisms and transports substances. The A/G ratio is an indicator of immune status, and a high ratio suggests health problems in the organism [35]. In the current study, the A/G ratio observed for the raw garlic and garlic powder groups did not differ significantly compared to the control group, suggesting these treatments had no obvious negative impacts on maintenance of homeostasis of the fish.

\section{Conclusion}

This study demonstrated that garlic-containing diets could enhance the nonspecific immune response of groupers. Although garlic supplementation did not increase growth performance, the fish fed with garlic had an enhanced ability to resist $V$. alginolyticus infection. Furthermore, raw garlic had a greater effect in grouper's than garlic powder did. Therefore, we recommend using raw garlic to achieve economic benefits, and application of garlic in aquaculture can reduce antibiotic use and increase aquatic product safety.

\section{Declaration of competing interest}

None of the authors has a financial relationship with a commercial entity that has an interest in the subject of this manuscript.

\section{Acknowledgements}

We would like to thank NTOU Aquatic Animal Center for providing laboratory animals. 


\section{References}

[1] Qu M, Tang W, Liu QH, Wang DX, Ding SX. Genetic diversity within grouper species and a method for interspecific hybrid identification using DNA barcoding and RYR3 marker. Mol Phylogenet Evol 2018;121:46-51.

[2] Ma HL, Xie JF, Weng SP, Zhou TH, He JG. Co-infection of megalocytivirus and viral nervous necrosis virus in a very severe mass mortality of juvenile orange-spotted groupers (Epinephelus coioides). Aquaculture 2012;358:170-5.

[3] Okocha RC, Olatoye IO, Adedeji OB. Food safety impacts of antimicrobial use and their residues in aquaculture. Publ Health Rev 2018;39:21.

[4] Aslam B, Wang W, Arshad MI, Khurshid M, Muzammil S, Rasool MH, et al. Antibiotic resistance: a rundown of a global crisis. Infect Drug Resist 2018;11:1645-58.

[5] Smith NC, Rise ML, Christian SL. A Comparison of the Innate and adaptive Immune systems in cartilaginous fish, ray-finned fish, and lobe-finned fish. Front Immunol 2019;10:2292.

[6] Barman D, Nen P, Mandal S, Kumar V. Immunostimulants for aquaculture health management. J Mar Sci Res Dev 2013; 3(3):134.

[7] Samad APA, Santoso U, Lee MC, Nan FH. Effects of dietary katuk (Sauropus androgynus L. Merr.) on growth, non-specific immune and diseases resistance against Vibrio alginolyticus infection in grouper Epinephelus coioides. Fish Shellfish Immunol 2014;36(2):582-9.

[8] Kuo IP, Lee PT, Nan FH. Rheum officinale extract promotes the innate immunity of orange-spotted grouper (Epinephelus coioides) and exerts strong bactericidal activity against six aquatic pathogens. Fish Shellfish Immunol 2020;102:117-24.

[9] Lee PT, Liao ZH, Huang HT, Chuang CY, Nan FH. Betaglucan alleviates the immunosuppressive effects of oxytetracycline on the non-specific immune responses and resistance against Vibrio alginolyticus infection in Epinephelus fuscoguttatus $\times$ Epinephelus lanceolatus hybrids. Fish Shellfish Immunol 2020;100:467-75.

[10] Maqsood S, Singh P, Samoon MH, Munir KJ. Emerging role of immunostimulants in combating the disease outbreak in aquaculture. Int Aquat Res 2011;3(3):147-63.

[11] Mastan SA. Use of immunostimulants in aquaculture disease management. Int J Fish Aquat Stud 2015;2(4):277-80.

[12] Omar SH, Al-Wabel NA. Organosulfur compounds and possible mechanism of garlic in cancer. Saudi Pharmaceut J 2010;18(1):51-8.

[13] Sahu S, Das BK, Mishra BK, Pradhan J, Sarangi N. Effect of Allium sativum on the immunity and survival of Labeo rohita infected with Aeromonas hydrophila. J Appl Ichthyol 2007; 23(1):80-6.

[14] Nya EJ, Austin B. Development of immunity in rainbow trout (Oncorhynchus mykiss, Walbaum) to Aeromonas hydrophila after the dietary application of garlic. Fish Shellfish Immunol 2011;30(3):845-50.

[15] Labrador JRP, Guinares RC, Hontiveros GJS. Effect of garlic powder-supplemented diets on the growth and survival of Pacific white leg shrimp (Litopenaeus vannamei). 2016. p. 1210066. 2(1).

[16] Abe K, Hori Y, Myoda T. Volatile compounds of fresh and processed garlic. Exp Ther Med 2020;19(2):1585-93.

[17] Motlag HA, Safari O, Selahvarzi Y, Baghalian A, Kia E. Nonspecific immunity promotion in response to garlic extract supplemented diets in female Guppy (Poecilia reticulata). Fish Shellfish Immunol 2020;97:96-9.

[18] Guo JJ, Kuo CM, Chuang YC, Hong JW, Chou RL, Chen TI. The effects of garlic-supplemented diets on antibacterial activity against Streptococcus iniae and on growth in orange-spotted grouper, Epinephelus coioides. Aquaculture 2012;364:33-8.
[19] Guo JJ, Kuo CM, Hong JW, Chou RL, Lee YH, Chen TI. The effects of garlic-supplemented diets on antibacterial activities against Photobacterium damselae subsp. piscicida and Streptococcus iniae and on growth in Cobia. Rachycentron canadum. Aquaculture 2015;435:111-5.

[20] Fujisawa H, Suma K, Origuchi $K$, Seki T, Ariga T. Thermostability of allicin determined by chemical and biological assays. Biosci Biotechnol Biochem 2008;72(11): 2877-83.

[21] Nehlah R, Firdaus-Nawi M, Nik-Haiha NY, Karim M, ZamriSaad M, Ina-Salwany MY. Recombinant vaccine protects juvenile hybrid grouper, Epinephelus fuscoguttatus x Epinephelus lanceolatus, against infection by Vibrio alginolyticus. Aquacult Int 2017;25(6):2047-59.

[22] Santarem MM, Figueras A. Leucocyte numbers and phagocytic activity in turbot Scophthalmus maximus following immunization with Vibrio damsela and Pasteurella piscicida $\mathrm{O}$ antigen bacterins. Dis Aquat Org 1995;23(3):213-20.

[23] Kiron V, Puangkaew J, Ishizaka K, Satoh S, Watanabe T. Antioxidant status and nonspecific immune responses in rainbow trout (Oncorhynchus mykiss) fed two levels of vitamin E along with three lipid sources. Aquaculture 2004;234(1-4): 361-79.

[24] Talpur AD, Ikhwanuddin M. Dietary effects of garlic (Allium sativum) on haemato-immunological parameters, survival, growth, and disease resistance against Vibrio harveyi infection in Asian sea bass, Lates calcarifer (Bloch). Aquaculture 2012;364:6-12.

[25] Regu M, Yilma Z, Seifu E. Effect of garlic (Allium sativum) and ginger (Zingiber officinale) powder on chemical composition and sensory property of Ayib - Ethiopian cottage cheese. Int Food Res J 2016;23(3):1226-32.

[26] Brown SP, Cornforth DM, Mideo N. Evolution of virulence in opportunistic pathogens: generalism, plasticity, and control. Trends Microbiol 2012;20(7):336-42.

[27] Biller JD, Takahashi LS. Oxidative stress and fish immune system: phagocytosis and leukocyte respiratory burst activity. An Acad Bras Cienc 2018;90(4):3403-14.

[28] Cannizzo ES, Clement CC, Sahu R, Follo C, Santambrogio L. Oxidative stress, inflamm-aging and immunosenescence. J Proteomics 2011;74(11):2313-23.

[29] Metaxa E, Deviller G, Pagand P, Alliaume C, Casellas C, Blancheton JP. High rate algal pond treatment for water reuse in a marine fish recirculation system: water purification and fish health. Aquaculture 2006;252(1):92-101.

[30] Amagase H, Petesch BL, Matsuura H, Kasuga S, Itakura Y. Intake of garlic and its bioactive components. J Nutr 2001; 131(3):955s-62s.

[31] Kodera Y, Ushijima M, Amano H, Suzuki JI, Matsutomo T. Chemical and biological properties of S-1-Propenyl-1Cysteine in aged garlic extract. Molecules 2017;22(4):570.

[32] Gopalakannan A, Arul V. Immunomodulatory effects of dietary intake of chitin, chitosan and levamisole on the immune system of Cyprinus carpio and control of Aeromonas hydrophila infection in ponds. Aquaculture 2006;255: 179-87.

[33] Hachimura S, Totsuka M, Hosono A. Immunomodulation by food: impact on gut immunity and immune cell function. Biosci Biotechnol Biochem 2018;82:584-99.

[34] Javed M, Ahmad MI, Usmani N, Ahmad M. Multiple biomarker responses (serum biochemistry, oxidative stress, genotoxicity and histopathology) in Channa punctatus exposed to heavy metal loaded waste water. Sci Rep 2017; $7(1)$.

[35] Wiegertjes GF, Stet RJM, Parmentier HK, vanMuiswinkel WB. Immunogenetics of disease resistance in fish: a comparative approach. Dev Comp Immunol 1996;20(6):365-81. 